\title{
Depression in Japanese Patients With Chronic Obstructive Pulmonary Disease: A Cross-Sectional Study
}

\author{
Nobuyuki Horita MD, Takeshi Kaneko MD PhD, Masaharu Shinkai MD PhD, \\ Makiko Yomota MD, Satoshi Morita MD PhD, Bruce K Rubin MEngr MD MBA PhD FAARC, \\ and Yoshiaki Ishigatsubo $\mathrm{MD} \mathrm{PhD}$
}

\begin{abstract}
BACKGROUND: Some investigations have revealed an association between depression and physical measurements of COPD patients in North America and Europe, but few related studies have been performed in Asia. METHODS: In this cross-sectional study, 84 consecutive, stable outpatients with COPD (mean \pm SD age $72.0 \pm 9.0$ y, percent-of-predicted $F E V_{1} 46 \pm 15 \%, 15$ [17.9\%] female) in a Japanese community hospital were recruited. "Probable depression" was defined as a score of $\geq 6$ on the short-form Geriatric Depression Scale (SF-GDS). Relationships among commonly used physical measurements, SF-GDS raw score, and probable depression were evaluated with the Spearman rank correlation test, multiple linear regression analysis, logistic regression analysis, and receiver operating characteristic curves. RESULTS: Thirty-two subjects $(\mathbf{3 8 . 1 \%})$ had probable depression. Body mass index, obstruction, dyspnea, exercise capacity index, percent-ofpredicted $\mathrm{FEV}_{1}$, Modified Medical Research Council dyspnea score, 6-min walk distance, and $\mathrm{S}_{\mathrm{pO}_{2}}$ had: simple correlations ( $\mathrm{r} 0.42-0.60, P<.001$ for all) with the SF-GDS raw score; partial correlations (r $0.25-0.51, P<.05$ for all) with the SF-GDS raw score after adjusting for demographic and social factors; association with probable depression in the logistic regression analysis after adjusting for demographic and social factors $(P<.05$ for all $)$; and areas under the receiver operating characteristic curve of $0.72-0.84(P<.001$ for any) for probable depression. CONCLUSIONS: Physical parameters were associated with depression in our Japanese COPD out-patients. Key words: depression; COPD; Japan; geriatric. [Respir Care 2013;58(7):1196-1203. (C) 2013 Daedalus Enterprises]
\end{abstract}

\section{Introduction}

COPD, defined as not fully reversible air-flow obstruction, ${ }^{1}$ is now the fourth leading cause of death in the world. ${ }^{2}$

\footnotetext{
Drs Horita and Dr Ishigatsubo are affiliated with the Department of Internal Medicine and Clinical Immunology, Yokohama City University Graduate School of Medicine, Yokohama, Japan. Drs Kaneko and Shinkai are affiliated with the Respiratory Disease Center; and Dr Morita is affiliated with the Department of Biostatistics and Epidemiology, Yokohama City University Medical Center, Yokohama, Japan. Dr Yomota is affiliated with the Department of Allergy and Respiratory Medicine, Fraternity Memorial Hospital, Tokyo, Japan. Dr Rubin is affiliated with the Department of Pediatrics, Virginia Commonwealth University, Richmond, Virginia.
}

The authors have disclosed no conflicts of interest.

Supplementary material related to this paper is available at http:// www.rcjournal.com.
Among the many aspects of COPD, depression is a serious concern, because it is generally associated with longer hospitalization, poor survival rate, and impaired physical and social functioning. ${ }^{3}$ Patients with depression also characteristically make fewer attempts to improve their health. ${ }^{4-6}$ Therefore, examining symptoms of depression is an important part of comprehensive COPD treatment.

The prevalence and incidence of depression among COPD patients are high, but the depression is often underdiagnosed and undertreated in these patients. ${ }^{7-11}$ Inade-

\footnotetext{
Correspondence: Takeshi Kaneko MD PhD, Respiratory Disease Center, Yokohama City University Medical Center, 4-57 Urafune, Minami-ku, Yokohama City, 232-0024, Japan. E-mail: takeshi@med.yokohama-cu. ac.jp.

DOI: $10.4187 /$ respcare. 02065
} 
quate treatment for depression leads to insufficient care, poor quality of life, and premature death. ${ }^{12}$ Several risk factors are well known to predict depression in COPD patients: female, ${ }^{7,13}$ current smoking, ${ }^{7,12,14}$ poor quality of life, $,{ }^{9}, 12-14$ long-term oxygen therapy (LTOT), ${ }^{15}$ living alone, ${ }^{16}$ and low social status. ${ }^{7}$ Studies in North America and Europe have evaluated the association between depression and physical factors such as percent-of-predicted $\mathrm{FEV}_{1}$, 6-min walk distance (6MWD), and Modified Medical Research Council (MMRC) dyspnea score, 3,13,14,16-30 but few studies have focused on the association between depression and COPD in Asians. Compared to whites, Asians generally exhibited elevated levels of depression. ${ }^{31,32}$ A study recently published in Japan reported that the prevalence of depression among COPD elderly in-patients (mean age of $72.7 \mathrm{y}$ ) was as high as $48.6 \% .^{33}$

Thus, investigations of depression in Asian out-patients with COPD are warranted. If the link between depression and commonly used physical measurements becomes clear, physicians could respond by screening such patients for depression. This would increase the rate of diagnosis and adequate treatment of depression.

This cross-sectional study evaluated the prevalence of depression and the association between depression and physical measurements such as percent-of-predicted $\mathrm{FEV}_{1}$, MMRC dyspnea score, and 6MWD, in Japanese COPD out-patients.

\section{Methods}

The study was performed in the Department of Allergy and Respiratory Medicine, Fraternity Memorial Hospital, Tokyo, Japan, and in the Department of Internal Medicine and Clinical Immunology, Yokohama City University Graduate School of Medicine, Yokohama, Japan.

\section{Procedure}

All patients who visited the Fraternity Memorial Hospital from November 2010 to February 2011 for treatment of COPD were considered as possible study subjects. First, the investigators screened patients by reviewing their charts. Then investigators met all of the candidates and evaluated them for the inclusion criteria. Patients who satisfied the criteria and agreed to participate were then surveyed.

\section{Study Population}

The inclusion criteria were:

- COPD diagnosis as defined by the Global Initiative for Chronic Obstructive Lung Disease (GOLD) ${ }^{1}$ (spirometry was newly performed at this time)

\section{QUICK LOOK}

\section{Current knowledge}

Depression is a common comorbidity in patients with COPD, and is associated with longer hospitalization, poor survival, and impaired physical and social functioning. Depression is under-diagnosed in COPD patients, and the research has mainly been in Europe and North America.

\section{What this paper contributes to our knowledge}

In Japanese patients with COPD, the prevalence and severity of depression were associated with the severity of lung impairment. The Global Initiative for Chronic Obstructive Lung Disease (GOLD) COPD stage, BODE (body mass index, air-flow obstruction, dyspnea, and exercise capacity) index, percent-of-predicted $\mathrm{FEV}_{1}$, 6-min walk distance, and $\mathrm{S}_{\mathrm{pO}_{2}}$ were all worse in patients with depression.

- Stable medical condition, without exacerbation or infection in the preceding 2 weeks

- No orthopedic problem interfering with the 6-min walk test

- $\mathrm{S}_{\mathrm{pO}_{2}} \geq 90 \%$ on ambient air

- Able to safely complete the 6-min walk test

- Not currently taking an antidepressant (the degree of depression may be affected by antidepressant; depressed patients not taking antidepressants were not excluded)

- Absence of severe disease such as active malignancy or human immunodeficiency virus, which may influence the degree of depression.

We approached 191 patients for recruitment, of whom 107 were excluded, for the following reasons: 25 refused to participate, 23 missed appointments, 32 did not meet COPD diagnostic criteria $\left(\mathrm{FEV}_{1} / \mathrm{FEV}>70 \%[n=15]\right.$; $>12 \%$ reversibility after inhaled salbutamol $[n=15]$; CT image not compatible $[n=2]), 3$ had had recent exacerbations, 6 had orthopedic problems, 4 had $\mathrm{S}_{\mathrm{pO}_{2}}<90 \%$ on ambient air, 1 was taking an antidepressant, and 3 had human immunodeficiency virus or malignancy. Some patients had 2 or more reasons for exclusion. Finally, 84 COPD patients were included in the study. We obtained written informed consent from all subjects. No subjects were on respiratory rehabilitation, as our facility does not provide that for out-patients. This study was approved by the institutional review boards at Yokohama City University Hospital and Fraternity Memorial Hospital. 
Table 1. Subject Characteristics and Correlation With SF-GDS Depression Score

\begin{tabular}{|c|c|c|c|c|}
\hline & $\begin{array}{c}\text { All } \\
\text { Subjects }\end{array}$ & Depression & $\begin{array}{c}\text { No } \\
\text { Depression }\end{array}$ & $P$ \\
\hline$n$ & 84 & 32 & 52 & \\
\hline SF-GDS depression score, mean \pm SD & $4.7 \pm 3.5$ & $8.4 \pm 2.5$ & $2.4 \pm 1.5$ & $<.001$ \\
\hline Age, mean $\pm \mathrm{SD}$ & $72.0 \pm 9.0$ & $74.1 \pm 9.1$ & $70.7 \pm 8.7$ & .09 \\
\hline Female, no. (\%) & $15(17.9)$ & $9(18.1)$ & $6(11.5)$ & .08 \\
\hline Smoking history, mean \pm SD pack-years & $52.6 \pm 29.8$ & $59.1 \pm 48.5$ & $34.7 \pm 25.9$ & .11 \\
\hline Current smoker, no. (\%) & $13(15.5)$ & $5(15.6)$ & $8(15.4)$ & .98 \\
\hline Low economic status, no. (\%) & $11(13.1)$ & $8(25.0)$ & $3(5.8)$ & .02 \\
\hline LTOT, no. $(\%)$ & $16(19.0)$ & $13(40.6)$ & $3(5.8)$ & $<.001$ \\
\hline Living alone, no. (\%) & $11(13.1)$ & $7(21.9)$ & $4(7.7)$ & .09 \\
\hline Widowed or divorced, no. (\%) & $6(7.1)$ & $4(12.5)$ & $2(3.8)$ & .20 \\
\hline GOLD COPD stage, no. (\%) & & & & $<.001$ \\
\hline I & $2(2.4)$ & $0(0.0)$ & $2(3.8)$ & \\
\hline II & $27(32.1)$ & $6(18.8)$ & $21(40.4)$ & \\
\hline III & $43(51.2)$ & $15(46.9)$ & $28(53.8)$ & \\
\hline IV & $12(14.3)$ & $11(34.4)$ & $1(1.9)$ & \\
\hline BODE index, mean $\pm \mathrm{SD}$ & $3.6 \pm 2.5$ & $5.5 \pm 2.7$ & $2.4 \pm 1.5$ & $<.001$ \\
\hline Body mass index, mean $\pm \mathrm{SD} \mathrm{kg} / \mathrm{m}^{2}$ & $21.0 \pm 3.0$ & $21.0 \pm 3.6$ & $21.1 \pm 2.6$ & .94 \\
\hline $\mathrm{FEV}_{1}$, mean $\pm \mathrm{SD} \%$ predicted & $46 \pm 15$ & $38 \pm 14$ & $51 \pm 13$ & $<.001$ \\
\hline MMRC dyspnea score, mean \pm SD & $1.4 \pm 1.4$ & $2.5 \pm 1.3$ & $0.8 \pm 0.9$ & $<.001$ \\
\hline $6 \mathrm{MWD}$, mean $\pm \mathrm{SD} \mathrm{m}^{*}$ & $409 \pm 160$ & $232 \pm 183$ & $477 \pm 96$ & $<.001$ \\
\hline $\mathrm{S}_{\mathrm{pO}_{2}}$, mean $\pm \mathrm{SD} \%$ & $94.9 \pm 2.1$ & $93.5 \pm 2.1$ & $95.6 \pm 1.8$ & $<.001$ \\
\hline Anticholinergics, no. (\%) & $67(79.8)$ & $24(75.0)$ & $43(82.7)$ & .42 \\
\hline Long-acting $\beta$ agonist, no. (\%) & $38(45.2)$ & $15(46.9)$ & $23(44.2)$ & .83 \\
\hline Theophylline, no. (\%) & $26(31.0)$ & $8(25.0)$ & $18(34.6)$ & .47 \\
\hline Inhaled corticosteroids, no. (\%) & $16(19.0)$ & $6(18.8)$ & $10(19.2)$ & $>.99$ \\
\hline $\begin{array}{l}\text { * The minimum clinically important difference for 6-mi } \\
\text { SF-GDS = short form of the Geriatric Depression Scale } \\
\text { LTOT = long-term oxygen therapy } \\
\text { GOLD = Global Initiative for Chronic Obstructive Lun } \\
\text { BODE = body mass index, air-flow obstruction, dyspne } \\
\text { MMRC = Modified Medical Research Council dyspnea }\end{array}$ & IWD) is $54 \mathrm{~m}^{40}$ & & & \\
\hline
\end{tabular}

\section{Short Form of the Geriatric Depression Scale}

The short form of the Geriatric Depression Scale (SFGDS), consisting of 15 yes-or-no questions, was originally designed as a depression screening tool. A total score $\geq 6$ indicates probable depression. ${ }^{22,34}$ While the SF-GDS was primarily used as a screening tool, Giordano showed that SF-GDS score correlates with the Beck depression inventory score, one of the most widely used instruments for measuring the severity of depression $(\mathrm{r}=0.78, P<.001){ }^{35}$ This scale was originally developed for geriatrics but was later validated for younger adults as well. ${ }^{34}$

\section{Measurement of Other Clinical Parameters}

We selected the following clinical measurements: physical measurements of COPD, GOLD stage, ${ }^{1}$ BODE (body mass index, obstruction, dyspnea, and exercise capacity) index ${ }^{36}$ and its components, $\mathrm{S}_{\mathrm{pO}_{2}}$; and known demographic and social risk factors for depression among COPD pa- tients, including age (depression is more prevalent in younger patients), sex (depression is more prevalent in females), smoking history (in pack-years), current smoking, low economic status, use of LTOT, living alone, and marital status (widowed or divorced). ${ }^{37}$

GOLD stage ${ }^{1}$ is primarily based on percent-of-predicted $\mathrm{FEV}_{1}$, and ranges from I (mild) to IV (very severe). The BODE index ${ }^{36}$ is a comprehensive prognostic index with 4 components, and the total score ranges from 0 to 10 . The score of 10 indicates the poorest prognosis. The MMRC dyspnea scale score ranges from 0 to 4 , with 4 indicating the severest dyspnea. Trained medical technicians performed spirometry (Autospiro AS-407, Minato, Osaka, Japan). 6MWD was obtained by standardized method ${ }^{38}$ on a 108 meter rounded track, without oxygen supplementation. The subject inhaled $1.5 \mathrm{mg}$ of salbutamol via nebulizer for 20 min, and then $\mathrm{FEV}_{1}$ was measured. $\mathrm{S}_{\mathrm{pO}_{2}}$ was recorded with a portable pulse oximeter (Pulsox-M, Minolta, Osaka, Japan) after a 5-min resting period in a sitting position. Predicted spirogram values were based on a 

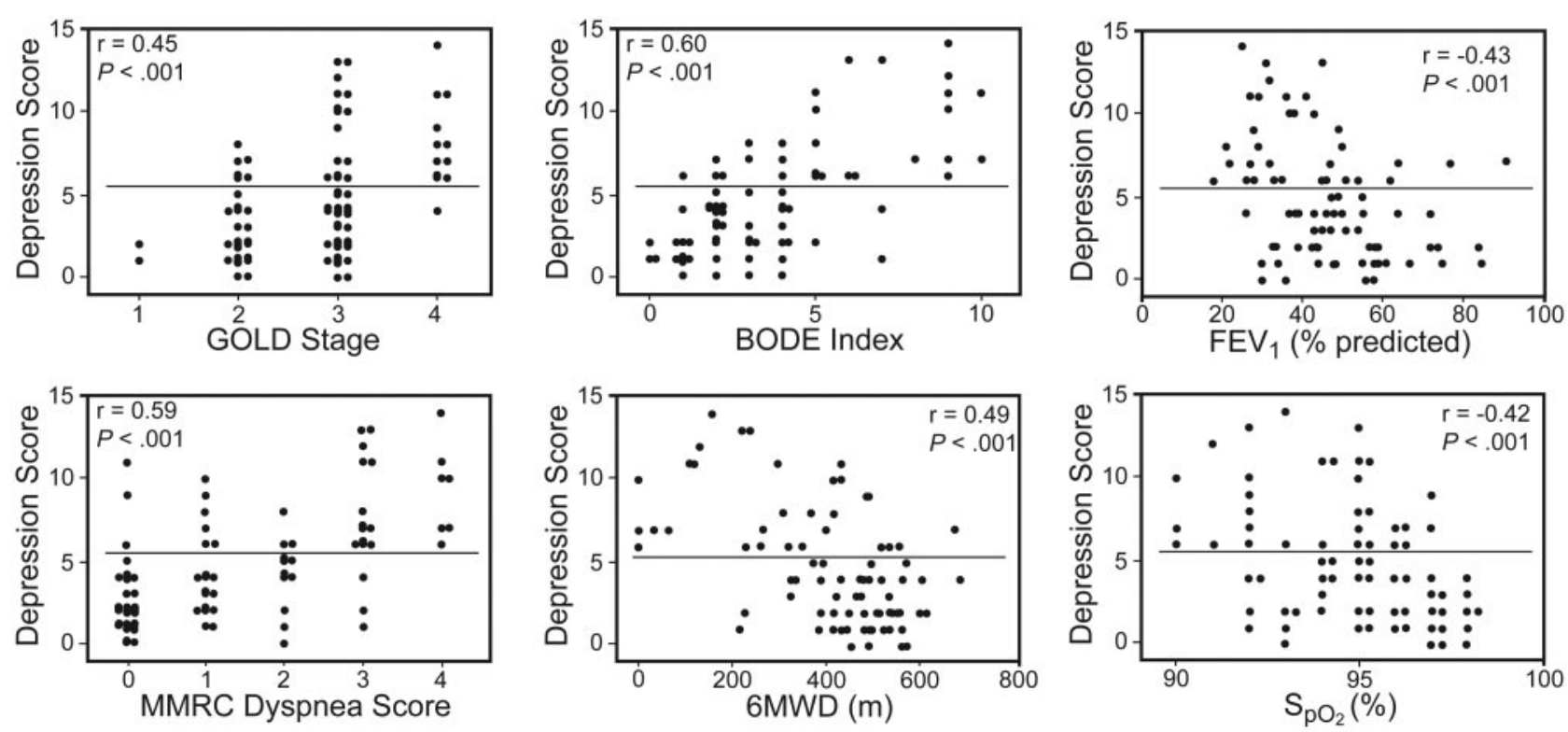

Fig. 1. Scatter plots of scores on the short-form of the Geriatric Depression Scale (SF-GDS) versus Global Initiative for Chronic Obstructive Lung Disease (GOLD) stage, BODE (body mass index, obstruction, dyspnea, and exercise capacity) index, percent-of-predicted FEV ${ }_{1}$, Modified Medical Research Council (MMRC) dyspnea score, 6-min walk distance (6MWD), and $\mathrm{S}_{\mathrm{pO}_{2}}$ in subjects with COPD. Each dot represents one subject.

formula designed for Japanese subjects. ${ }^{39}$ Low economic status was defined as receiving supplemental security income from the Japanese government. This supplemental income is offered to approximately $1.5 \%$ of Japanese families.

\section{Statistical Analysis}

Data were analyzed using the unpaired Student $t$ test, the Fisher exact test, multiple linear regression analysis, logistic regression analysis, receiver operating characteristic curve, and Cochran-Armitage test. Rank correlation was evaluated with Spearman rank correlation test, whereby $\mathrm{r}<0.2$ indicated meaningless correlation, $0.2 \leq \mathrm{r}<0.4$ indicated weak correlation, $0.4 \leq \mathrm{r}<0.6$ indicated moderate correlation, $0.6 \leq \mathrm{r}<0.8$ indicated strong correlation, and $0.8 \leq \mathrm{r}$ indicated very strong correlation. The \pm sign always indicates standard deviation, not standard error. $P$ values $<.05$ were considered statistically significant. Statistical analyses were performed with statistics software (Excel Toukei, SSRI, Tokyo, Japan, and Prism 5, GraphPad Software, San Diego, California).

\section{Results}

Eighty-four subjects met the criteria for this study; 69 were male, and 15 were female. The average age was $72.0 \pm 9.0$ y. Percent-of-predicted $\mathrm{FEV}_{1}$ was $45.9 \pm 14.7 \%$. Results from the SF-GDS indicated that 32 (38.1\%) subjects had probable depression, while 52 (61.9\%) did not.
Demographic, social, and physical measurements among all subjects, subjects with probable depression (SFGDS $\geq 6$ ), and subjects without probable depression (SFGDS $<6$ ) are summarized in Table $1 .{ }^{40}$ Subjects with and without probable depression had statistically significant $(P<.05)$ differences in economic status, LTOT use, GOLD stage, BODE index, percent-of-predicted $\mathrm{FEV}_{1}$, MMRC dyspnea score, 6MWD, and $\mathrm{S}_{\mathrm{pO}_{2}}$.

GOLD stage, BODE index, percent-of-predicted $\mathrm{FEV}_{1}$, MMRC dyspnea score, 6MWD, and $\mathrm{S}_{\mathrm{pO}_{2}}$ each had a significant rank correlation of $\mathrm{r}>0.4$ with raw SF-GDS score. Scatter plots for SF-GDS and 6 physical measurements are shown in Figure 1. These 6 physical measurements except for GOLD stage, which is not a continuous variable, had significant associations with raw SF-GDS score, even after adjusting for 8 demographic and social factors such as use of LTOT (Table 2).

Probable depression significantly increased as BODE index, percent-of-predicted $\mathrm{FEV}_{1}$, MMRC dyspnea score, 6MWD, and $\mathrm{S}_{\mathrm{pO}_{2}}$ decreased in models adjusting for 8 demographic and social factors such as use of LTOT (Table 3).

Receiver operating characteristic curves to predict probable depression by each physical factor are shown in Figure 2. The range for area under the curve was $0.719-0.841$ for the 6 parameters $(P<.001$ for all). Receiver operating characteristic curves were allocated near the $\mathrm{Y}$-axis, especially when sensitivity was $<0.3$, meaning each parameter had good specificity rather than sensitivity. The 3 fac- 
Table 2. Multiple Linear Regression Analysis* for the Short Form of the Geriatric Depression Scale

\begin{tabular}{|c|c|c|}
\hline & $\begin{array}{c}\text { Partial } \\
\text { Correlation } \\
\text { Coefficient }\end{array}$ & $P$ \\
\hline BODE index & 0.51 & $<.001$ \\
\hline Percent-of-predicted FEV & -0.30 & .009 \\
\hline MMRC dyspnea score & 0.42 & $<.001$ \\
\hline 6MWD & -0.34 & .003 \\
\hline $\mathrm{S}_{\mathrm{pO}_{2}}$ & -0.25 & .03 \\
\hline \multicolumn{3}{|c|}{$\begin{array}{l}\text { * With } 8 \text { demographic and social factors and } 1 \text { physical factor. } \\
\text { BODE = body mass index, air-flow obstruction, dyspnea, exercise capacity } \\
\text { MMRC = Modified Medical Research Council dyspnea scale } \\
\text { 6MWD = 6-min walk distance }\end{array}$} \\
\hline
\end{tabular}

Table 3. Multiple Logistic Regression Analysis* for Probable Depression (SG-GDS Score $\geq 6$ )

\begin{tabular}{lcr}
\hline \hline & Odds Ratio & \multicolumn{1}{c}{$P$} \\
\hline BODE index & 2.3 & $<.001$ \\
Percent-of-predicted $\mathrm{FEV}_{1}(10 \%)$ & 0.48 & .008 \\
MMRC & 3.6 & $<.001$ \\
$6 \mathrm{MWD}(100 \mathrm{~m})$ & 0.45 & .003 \\
$\mathrm{~S}_{\mathrm{PO}_{2}}$ & 0.72 & .03
\end{tabular}

* With 8 demographic and social factors and 1 physical factor. Example: a 100-m increase in 6-min walk distance (6MWD) is equivalent to an odds ratio of 0.45 for probable depression after adjusting for the 8 demographic and social factors.

BODE $=$ body mass index, air-flow obstruction, dyspnea, exercise capacity

MMRC $=$ Modified Medical Research Council dyspnea scale

tors with the highest area under the curve were BODE index, MMRC dyspnea score, and 6MWD.

The positive predictive values for probable depression were 0.73 for MMRC dyspnea score of 2.5 , and 0.86 for 6MWD of $250 \mathrm{~m}$.

\section{Discussion}

In the current study, the severity and prevalence of depression were associated with COPD severity measured by GOLD stage, BODE index, percent-of-predicted $\mathrm{FEV}_{1}$, MMRC dyspnea score, 6MWD, and $\mathrm{S}_{\mathrm{pO}_{2}}$. Previous studies evaluating the association between physical factors and depression are summarized in Table 4 . The first was conducted by Light in $1985 .{ }^{17}$ Until 2007, most studies denied an association between depression and physical measurements of COPD. In contrast, most studies since 2008 have affirmed a positive association between depression and physical measurements of COPD. That lack of concordance might be owing to the wide variation in nationality, measurement tools, study design, and diagnostic criteria. ${ }^{41}$ The homogenous severity of COPD makes it especially difficult to detect a relationship. For example, most studies

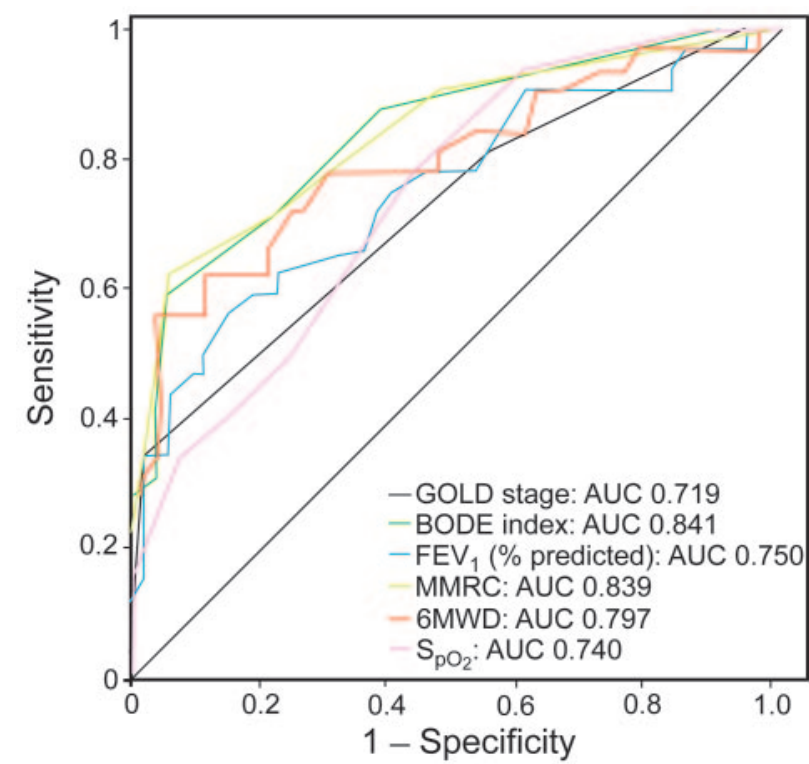

Fig. 2. Receiver operating characteristic curves for depression versus Global Initiative for Chronic Obstructive Lung Disease (GOLD) stage, BODE (body mass index, obstruction, dyspnea, and exercise capacity) index, percent-of-predicted $\mathrm{FEV}_{1}$, Modified Medical Research Council (MMRC) dyspnea score, 6-min walk distance (6MWD), and $\mathrm{S}_{\mathrm{pO}_{2}}$ in subjects with COPD. AUC = area under the receiver operating characteristic curve.

found a significant relationship between dyspnea and depression; however, some studies conducted with subjects who had relatively mild obstruction did not find an association. ${ }^{21,25}$ Similarly, a study of subjects who had relatively severe disease found no association between depression and physical parameters. ${ }^{17}$

Even though MMRC dyspnea score and 6MWD are simple parameters of COPD, their links with depression are strong. The positive predictive values in this study were 0.73 for MMRC dyspnea score of 2.5 , and 0.86 for $6 \mathrm{MWD}$ of $250 \mathrm{~m}$. If patients have worse dyspnea or limited exercise capacity, they should be screened for depression.

The associations between depression and some physical parameters are indisputable, but the interpretation is difficult. The simplest explanation is that depression is caused by COPD symptoms or limited quality of life. Another explanation is that depression makes physical signs and symptoms worse. The following evidence supports this hypothesis: subjective sensation of dyspnea increased with depression, even with normal lung function, ${ }^{42}$ and $6 \mathrm{MWD}$ depends on both physical and psychological factors. ${ }^{43,44}$ The other explanation is that systemic inflammation lowers both physical and mental status. There is a recent accumulation of evidence that somatic factors such as inflammation cytokines are also related to depression in COPD patients. ${ }^{45,46}$ Further research is expected to clarify the interaction between physical factors and depression. 
Depression in Japanese Patients With Chronic Obstructive Pulmonary Disease

Table 4. Summary of Studies Evaluating the Relationship Between Physical Factors and Depression

\begin{tabular}{|c|c|c|c|c|c|c|c|c|c|c|c|}
\hline \multirow[b]{2}{*}{ First Author } & \multirow[b]{2}{*}{ Year } & \multirow[b]{2}{*}{ Country } & \multicolumn{6}{|c|}{ Relationship With Physical Factors } & \multirow{2}{*}{$\begin{array}{c}\text { Prevalence } \\
(\%)\end{array}$} & \multirow{2}{*}{$\begin{array}{l}\text { Depression } \\
\text { Scale and } \\
\text { Score }\end{array}$} & \multirow[b]{2}{*}{ COPD Severity $^{\dagger}$} \\
\hline & & & BMI & $\mathrm{FEV}_{1}$ & Dyspnea & Exercise* & $\begin{array}{l}\text { BODE } \\
\text { Index }\end{array}$ & $\begin{array}{c}\mathrm{O} 2 \\
\text { Saturation }\end{array}$ & & & \\
\hline Light $^{17}$ & 1985 & United States & & $\circ$ & & o & & o & 42 & $\mathrm{BDI}>15$ & $\mathrm{FEV}_{1} \% 29 \pm 9 \%$ \\
\hline Mishima $^{23}$ & 1996 & Japan & & $\circ$ & $\bullet$ & & & ० & 19 & $\mathrm{HAD}>10$ & $\mathrm{FEV}_{1} 0.77 \pm 0.45 \mathrm{~L}$ \\
\hline Yohannes $^{18}$ & 1998 & United Kingdom & 0 & ○ & ○ & o & & & 46 & BASDEC $\geq 7$ & $\mathrm{FEV}_{1} \% 51 \pm 20 \%$ \\
\hline Borak $^{24}$ & 1998 & Poland & & ○ & & ○ & & $\bullet$ & 18 & $\mathrm{BDI} \geq 15$ & $\mathrm{FEV}_{1} \% 32 \pm 14 \%$ \\
\hline van Manen ${ }^{16}$ & 2002 & Netherlands & & $\#$ & & & & & 22 & CES-D $\geq 16$ & $\begin{array}{l}\text { Moderate } 63 \% \\
\text { Severe and very } \\
\text { severe } 37 \%\end{array}$ \\
\hline Wagena $^{19}$ & 2005 & Netherlands & & o & & & & & 30 & $\mathrm{BDI} \geq 15$ & $\mathrm{FEV}_{1} \% 56 \pm 27 \%$ \\
\hline Chavannes $^{25}$ & 2005 & Netherlands & $\bullet$ & ○ & \# & & & & 27 & $\mathrm{BDI}>10$ & $\mathrm{FEV}_{1} \% 64 \pm 19 \%$ \\
\hline Di Marco ${ }^{13}$ & 2006 & Italy & ○ & ○ & $\bullet$ & & & o & 19 & $\mathrm{SDS}>50$ & $\mathrm{FEV}_{1} \% 54 \pm 1 \%$ \\
\hline Hynninen $^{30}$ & 2007 & Norway & & o & & & & & 35 & BDI $2 \geq 20$ & $\mathrm{FEV}_{1} \% 54 \pm 24 \%$ \\
\hline Quint $^{26}$ & 2008 & United Kingdom & & & $\bullet$ & & & & 41 & CED-D $\geq 16$ & $\mathrm{FEV}_{1} \% 47 \pm 19 \%$ \\
\hline Bentsen $^{27}$ & 2008 & Norway & & & & $\bullet$ & & & NA & HAD & $\mathrm{FEV}_{1} \% 46 \pm 15 \%$ \\
\hline Funk $^{20}$ & 2009 & Austria & ० & $\#$ & $\bullet$ & $\bullet$ & $\bullet$ & & 52 & $\mathrm{HAD} \geq 8$ & $\mathrm{FEV}_{1} \% 45 \pm 19 \%$ \\
\hline $\mathrm{Ng}^{21}$ & 2009 & Singapore & & $\bullet$ & $\#$ & & & & 23 & SF-GDS $\geq 5$ & $\begin{array}{l}\text { Mild } 56 \% \\
\text { Moderate } 34 \% \\
\text { Severe and very } \\
\quad \text { severe } 10 \%\end{array}$ \\
\hline Omachi $^{22}$ & 2009 & United States & & $\bullet$ & & $\bullet$ & $\bullet$ & $\bullet$ & 27 & SF-GDS $\geq 6$ & $\mathrm{FEV}_{1} \% 62 \pm 23 \%$ \\
\hline Al-shair ${ }^{28}$ & 2009 & United Kingdom & ० & ○ & \# & $\bullet$ & $\bullet$ & & $\begin{array}{l}24 \\
19\end{array}$ & $\begin{array}{l}\text { CES-D } \geq 16 \\
\text { BASDEC } \geq 7\end{array}$ & $\mathrm{FEV}_{1} \% 52 \pm 18 \%$ \\
\hline Borge $^{29}$ & 2010 & Norway & & o & $\bullet$ & & & & NA & HAD & $\mathrm{FEV}_{1} \% 59 \pm 23 \%$ \\
\hline Hanania $^{14}$ & 2011 & $\begin{array}{l}\text { United States, } \\
\text { et cetera }\end{array}$ & ० & $\#$ & $\bullet$ & $\#$ & $\bullet$ & $\#$ & 26 & CES-D $\geq 16$ & $\mathrm{FEV}_{1} \% 48 \pm 16 \%$ \\
\hline Iguchi $^{33}$ & 2012 & Japan & & $\bullet$ & & & & & 49 & CES-D $\geq 16$ & $\mathrm{FEV}_{1} \% 37 \pm 18 \%$ \\
\hline $\begin{array}{l}\text { Horita } \\
\quad \text { (present study) }\end{array}$ & 2012 & Japan & $\circ$ & $\bullet$ & $\bullet$ & $\bullet$ & $\bullet$ & $\bullet$ & 38 & SF-GDS $\geq 6$ & $\mathrm{FEV}_{1} \% 46 \pm 15 \%$ \\
\hline
\end{tabular}

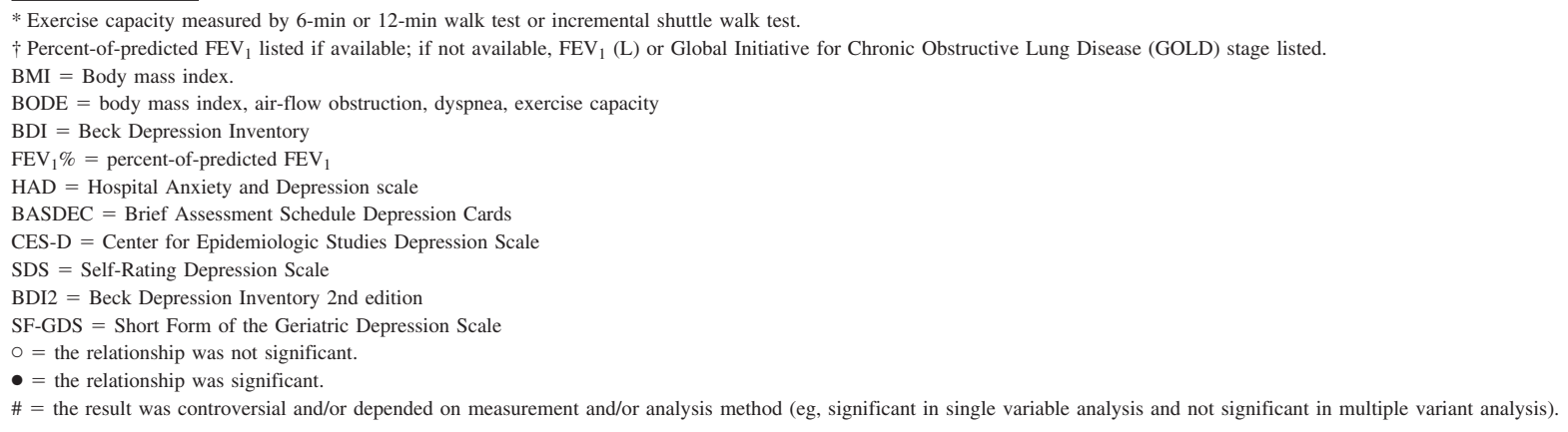

Some possible demographic and social risk factors did not prove to be related to depression in this study. This may be because this study was not designed to investigate such relationships. Our cohort did not include enough subjects with these risk factors to research the association.

MMRC dyspnea score and 6MWD had stronger associations with depression than did percent-of-predicted $\mathrm{FEV}_{1}$ in our study. The severity of COPD has traditionally been assessed via percent-of-predicted $\mathrm{FEV}_{1} \cdot{ }^{1}$ However, whether the current percent-of-predicted $\mathrm{FEV}_{1}$ grading scale is an ideal single parameter for severity of COPD has long been discussed. The importance of dyspnea and ex- ercise tolerance has recently been emphasized, because percent-of-predicted $\mathrm{FEV}_{1}$ underestimates the importance of the extra-pulmonary manifestations of COPD. ${ }^{36,47,48}$ Our study confirmed the superiority of MMRC dyspnea score and 6MWD over percent-of-predicted $\mathrm{FEV}_{1}$.

We also measured the prevalence of depression in our Japanese out-patient cohort (38.1\%). Iguchi's recent study of Japanese COPD in-patients reported a prevalence of $49 \% .{ }^{33}$ It is difficult to compare prevalence in studies that vary with respect to patient background, COPD severity, depression scales, and cutoff values for depression. The prevalence of depression in Japanese patients, both our 


\section{Depression in Japanese Patients With Chronic Obstructive Pulmonary Disease}

cohort and that studied by Iguchi, was greater than in patients in most other countries (see Table 4). In 1996, Mishima reported that the prevalence of depression was as low as $19 \%{ }^{23}$; however, the cutoff value (10 points on the Hospital Anxiety and Depression scale) is higher than the usually used cutoff of 8 points. ${ }^{20}$ Among European countries the prevalence of depression is especially high in the United Kingdom (see Table 4).

\section{Limitations}

This study had some limitations. First, the cohort size is not large enough to warrant a solid conclusion. Second, our study design had possible selection bias, because:

- More than $90 \%$ of COPD patients in Japan have emphysema. In Western countries, emphysema type is less common.

- In the recruiting process, 25 patients refused to participate, and 23 were excluded because they missed their appointments in the recruitment process. This may also have caused selection bias, because depressed patients are usually less motivated to participate in this kind of study.

- One patient $(0.5 \%)$ was excluded because of antidepressant use.

- The majority of subjects were male.

- There were several confounders, such as socio-economic status.

\section{Conclusions}

In conclusion, COPD parameters including GOLD stage, BODE index, percent-of-predicted $\mathrm{FEV}_{1}$, MMRC dyspnea score, $6 \mathrm{MWD}$, and $\mathrm{S}_{\mathrm{pO}_{2}}$ were generally associated with depression in our Japanese cohort. Dyspnea and exercise tolerance were especially important factors estimating depression.

\section{ACKNOWLEDGMENTS}

We thank Mr Masaya Narisada and Mrs Rikako Narisada for their advice on statistics, and Mrs Yoriko Inoue for her editorial assistance.

\section{REFERENCES}

1. Rabe KF, Hurd S, Anzueto A, Barnes PJ, Buist SA, Calverley P, et al. Global strategy for the diagnosis, management, and prevention of chronic obstructive pulmonary disease: GOLD executive summary. Am J Respir Crit Care Med 2007;176(6):532-555.

2. Mannino DM, Ford ES, Redd SC. Obstructive and restrictive lung disease and markers of inflammation: data from the Third National Health and Nutrition Examination. Am J Med 2003;114(9):758-762.

3. Ng TP, Niti M, Tan WC, Cao Z, Ong KC, Eng P. Depressive symptoms and chronic obstructive pulmonary disease: effect on mortality, hospital readmission, symptom burden, functional status, and quality of life. Arch Intern Med 2007;167(1):60-67.

4. Dowson CA, Town GI, Frampton C, Mulder RT. Psychopathology and illness beliefs influence COPD self-management. J Psychosom Res 2004;56(3):333-340.

5. Norwood R, Balkissoon R. Current perspectives on management of co-morbid depression in COPD. COPD 2005;2(1):185-193.

6. Wilson I. Depression in the patient with COPD. Int J Chron Obstruct Pulmon Dis 2006;1(1):61-64.

7. Kunik ME, Roundy K, Veazey C, Souchek J, Richardson P, Wray NP, et al. Surprisingly high prevalence of anxiety and depression in chronic breathing disorders. Chest 2005;127(4):1205-1211.

8. Kessler R, Ståhl E, Vogelmeier C, Haughney J, Trudeau E, Löfdahl $\mathrm{CG}$, Partridge MR. Patient understanding, detection, and experience of COPD exacerbations: an observational, interview-based study. Chest 2006;130(1):133-142.

9. Cully JA, Graham DP, Stanley MA, Ferguson CJ, Sharafkhaneh A, Souchek J, et al. Quality of life in patients with chronic obstructive pulmonary disease and comorbid anxiety or depression. Psychosomatics 2006;47(4):312-319.

10. Davidson JR, Meltzer-Brody SE. The underrecognition and undertreatment of depression: what is the breadth and depth of the problem? J Clin Psychiatry 1999;60(Suppl 7):4-9; discussion 10-11.

11. Hirschfeld RM, Keller MB, Panico S, Arons BS, Barlow D, Davidoff F, et al. The National Depressive and Manic-Depressive Association consensus statement on the undertreatment of depression. JAMA 1997;277(4):333-340.

12. Gudmundsson G, Gislason T, Janson C, Lindberg E, Suppli Ulrik C, Brøndum E, et al. Depression, anxiety and health status after hospitalisation for COPD: a multicentre study in the Nordic countries. Respir Med 2006;100(1):87-93.

13. Di Marco F, Verga M, Reggente M, Maria Casanova F, Santus P, Blasi F, et al. Anxiety and depression in COPD patients: the roles of gender and disease severity. Respir Med 2006;100(10):1767-1774.

14. Hanania NA, Mullerova H, Locantore NW, Vestbo J, Watkins ML, Wouters EF, et al. Determinants of depression in the ECLIPSE chronic obstructive pulmonary disease cohort. Am J Respir Crit Care Med 2011;183(5):604-611.

15. Lacasse Y, Rousseau L, Maltais F. Prevalence of depressive symptoms and depression in patients with severe oxygen-dependent chronic obstructive pulmonary disease. J Cardiopulm Rehabil 2001;21(2): 80-86.

16. van Manen JG, Bindels PJ, Dekker FW, IJzermans CJ, van der Zee JS, Schade E. Risk of depression in patients with chronic obstructive pulmonary disease and its determinants. Thorax 2002;57(5):412-416.

17. Light RW, Merrill EJ, Despars JA, Gordon GH, Mutalipassi LR. Prevalence of depression and anxiety in patients with COPD. Relationship to functional capacity. Chest 1985;87(1):35-38.

18. Yohannes AM, Roomi J, Waters K, Connolly MJ. Quality of life in elderly patients with COPD: measurement and predictive factors. Respir Med 1998;92(10):1231-1236.

19. Wagena EJ, Arrindell WA, Wouters EF, van Schayck CP. Are patients with COPD psychologically distressed? Eur Respir J 2005; 26(2):242-248.

20. Funk GC, Kirchheiner K, Burghuber OC, Hartl S. BODE index versus GOLD classification for explaining anxious and depressive symptoms in patients with COPD - a cross-sectional study. Respir Res 2009;10:1.

21. Ng TP, Niti M, Fones C, Yap KB, Tan WC. Co-morbid association of depression and COPD: a population-based study. Respir Med 2009;103(6):895-901.

22. Omachi TA, Katz PP, Yelin EH, Gregorich SE, Iribarren C, Blanc $\mathrm{PD}$, Eisner MD. Depression and health-related quality of life in 


\section{Depression in Japanese Patients With Chronic Obstructive Pulmonary Disease}

chronic obstructive pulmonary disease. Am J Med 2009;122(8): 778.e9-e15.

23. Mishima M, Oku Y, Muro S, Hirai T, Chin K, Ohi M, et al. Relationship between dyspnea in daily life and psycho-physiologic state in patients with chronic obstructive pulmonary disease during longterm domiciliary oxygen therapy. Intern Med 1996;35(6):453-458.

24. Borak J, Chodosowska E, Matuszewski A, Zielinski J. Emotional status does not alter exercise tolerance in patients with chronic obstructive pulmonary disease. Eur Respir J 1998;12(2):370-373.

25. Chavannes NH, Huibers MJ, Schermer TR, Hendriks A, van Weel C, Wouters EF, et al. Associations of depressive symptoms with gender, body mass index and dyspnea in primary care COPD patients. Fam Pract 2005;22(6):604-607.

26. Quint JK, Baghai-Ravary R, Donaldson GC, Wedzicha JA. Relationship between depression and exacerbations in COPD. Eur Respir J 2008;32(1):53-60.

27. Bentsen SB, Henriksen AH, Wentzel-Larsen T, Hanestad BR, Wahl AK. What determines subjective health status in patients with chronic obstructive pulmonary disease: importance of symptoms in subjective health status of COPD patients. Health Qual Life Outcomes 2008;6:115.

28. Al-shair K, Dockry R, Mallia-Milanes B, Kolsum U, Singh D, Vestbo J. Depression and its relationship with poor exercise capacity, BODE index and muscle wasting in COPD. Respir Med 2009;103(10):15721579 .

29. Borge CR, Wahl AK, Moum T. Association of breathlessness with multiple symptoms in chronic obstructive pulmonary disease. J Adv Nurs 2010;66(12):2688-2700.

30. Hynninen MJ, Pallesen S, Nordhus IH. Factors affecting health status in COPD patients with co-morbid anxiety or depression. Int J Chron Obstruct Pulmon Dis 2007;2(3):323-328.

31. Young CB, Fang DZ, Zisook S. Depression in Asian-American and Caucasian undergraduate students. J Affect Disord 2010;125(1-3): 379-382.

32. Jamil H, Grzybowski M, Hakim-Larson J, Fakhouri M, Sahutoglu J, Khoury R, et al. Factors associated with self-reported depression in Arab, Chaldean, and African Americans. Ethn Dis 2008;18(4):464470.

33. Iguchi A, Senjyu H, Hayashi $Y$, Kanada R, Iwai S, Honda S, et al. Relationship between depression in patients with COPD and the percent predicted $\mathrm{FEV}_{1}$, BODE Index, and health-related quality of life. Respir Care 2013;58(2):334-339.

34. Ferraro FR, Chelminski I. Preliminary normative data on the Geriatric Depression Scale-Short Form (GDS-SF) in a young adult sample. J Clin Psychol 1996;52(4):443-447.

35. Giordano M, Tirelli P, Ciarambino T, Gambardella A, Ferrara N, Signoriello G, et al. Screening of depressive symptoms in young-old hemodialysis patients: relationship between Beck Depression Inven- tory and 15-item Geriatric Depression Scale. Nephron Clin Pract 2007;106(4):c187-c192.

36. Celli BR, Cote CG, Marin JM, Casanova C, Montes de Oca M, Mendez RA, et al. The body-mass index, airflow obstruction, dyspnea, and exercise capacity index in chronic obstructive pulmonary disease. N Engl J Med 2004;350(10):1005-1012.

37. Maurer J, Rebbapragada V, Borson S, Goldstein R, Kunik ME, Yohannes AM, et al. Anxiety and depression in COPD: current understanding, unanswered questions, and research needs. Chest 2008;134(4 Suppl):43S-56S.

38. American Thoracic Society Committee on Proficiency Standards for Clinical Pulmonary Function Laboratories. ATS statement: guidelines for the six-minute walk test. Am J Respir Crit Care Med 2002; 166(1):111-117.

39. Japanese Respiratory Society, Committee of Respiratory Physiology. Reference values of spirogram and arterial blood gas analysis for Japanese. Tokyo: Japanese Respiratory Society; 2001.

40. Redelmeier DA, Bayoumi AM, Goldstein RS, Guyatt GH. Interpreting small differences in functional status: the six minute walk test in chronic lung disease patients. Am J Respir Crit Care Med 1997; 155(4):1278-1282.

41. van Ede L, Yzermans CJ, Brouwer HJ. Prevalence of depression in patients with chronic obstructive pulmonary disease: a systematic review. Thorax 1999;54(8):688-692.

42. Çalikoglu M, Şahin G, Yazici AE, Yazici K, Özişik S. Pulmonary muscle strength, pulmonary function tests, and dyspnea in women with major depression. J Womens Health (Larchmt) 2004;13(1):9398.

43. Spruit MA, Watkins ML, Edwards LD, Vestbo J, Calverley PM, Pinto-Plata V, et al. Determinants of poor 6-min walking distance in patients with COPD: the ECLIPSE cohort. Respir Med 2010;104(6): 849-857.

44. Lord SR, Menz HB. Physiologic, psychologic, and health predictors of 6-minute walk performance in older people. Arch Phys Med Rehabil 2002;83(7):907-911.

45. Al-shair K, Kolsum U, Dockry R, Morris J, Singh D, Vestbo J. Biomarkers of systemic inflammation and depression and fatigue in moderate clinically stable COPD. Respir Res 2011;12:3.

46. Eagan TM, Ueland T, Wagner PD, Hardie JA, Mollnes TE, Damas $\mathrm{JK}$, et al. Systemic inflammatory markers in COPD: results from the Bergen COPD Cohort Study. Eur Respir J 2010;35(3):540-548.

47. van Schayck CP. Is lung function really a good parameter in evaluating the long-term effects of inhaled corticosteroids in COPD? Eur Respir J 2000;15(2):238-239.

48. Nishimura K, Izumi T, Tsukino M, Oga T. Dyspnea is a better predictor of 5-year survival than airway obstruction in patients with COPD. Chest 2002;121(5):1434-1440. 